\title{
(Mil) Do team processes really have an effect on clinical performance? A systematic literature review
}

\author{
J. Schmutz* and T. Manser
}

Industrial Psychology and Human Factors, Department of Psychology, University of Fribourg, Rue de Faucigny 2, 1700 Fribourg, Switzerland

* Corresponding author. E-mail: jan.schmutz@unifr.ch

\section{Editor's key points}

- This review has examined the impact of team process behaviours on clinical performance.

- Twenty-eight studies, which reported at least one relationship between team process or an intervention and outcome, were reviewed.

- Team process behaviours have been shown to influence performance.

- Training in team behaviours results in improved performance.
Summary. There is a growing literature on the relationship between team processes and clinical performance. The purpose of this review is to summarize these articles and examine the impact of team process behaviours on clinical performance. We conducted a literature search in five major databases. Inclusion criteria were: English peer-reviewed papers published between January 2001 and May 2012, which showed or tried to show (i) a statistical relationship of a team process variable and clinical performance or (ii) an improvement of a performance variable through a team process intervention. Study quality was assessed using predefined quality indicators. For every study, we calculated the relevant effect sizes. We included 28 studies in the review, seven of which were intervention studies. Every study reported at least one significant relationship between team processes or an intervention and performance. Also, some non-significant effects were reported. Most of the reported effect sizes were large or medium. The study quality ranged from medium to high. The studies are highly diverse regarding the specific team process behaviours investigated and also regarding the methods used. However, they suggest that team process behaviours do influence clinical performance and that training results in increased performance. Future research should rely on existing theoretical frameworks, valid, and reliable methods to assess processes such as teamwork or coordination and focus on the development of adequate tools to assess process performance, linking them with outcomes in the clinical setting.

Keywords: clinical competence; group processes; leadership; patient care team; patient safety
Breakdown in team processes such as coordination, leadership, or communication have frequently been associated with adverse events and patient harm ${ }^{1-3}$ and the effectiveness of such team processes is central to the successful provision of patient care. ${ }^{145}$ While recent reviews indicate that team processes are widely accepted as an important factor influencing clinical performance of medical teams, ${ }^{1}$ 5-8 a general framework is needed to classify and compare different studies on teamwork. In this review, we invoked McGrath's systemic input-process-output (IPO) framework ${ }^{9}$ that has served as a foundation for numerous studies in team research ${ }^{10-14}$ and has been adapted and used in clinical settings in recent years. ${ }^{5} 7$ 15-17

According to this framework, inputs are preconditions influencing the processes in the team (e.g. team climate, task structure, leadership style). Team processes are defined as the cognitive, verbal, and behavioural activities going on while the team is working together (i.e. team communication, team leadership, team coordination, and team decisionmaking). ${ }^{5} 1819$ Outputs are the product of these processes. Either patient outcomes or team outcomes can be considered as outputs in a clinical setting. ${ }^{5}$
The IPO framework conceptualizes performance as an output that is directly influenced by team processes, ${ }^{5} 9$ but does not provide explicit definitions of performance or a means by which to measure it. Various authors agree that there is both a process and an outcome-related aspect to performance. ${ }^{20-22}$ The distinction between outcome and process performance measures is not always consistently used in the literature but should be borne in mind when aiming to establish an empirical evidence base on the relationships between team processes and outcomes.

Outcome performance measures such as mortality, ${ }^{23}$ morbidity, ${ }^{23}$ or length of stay ${ }^{24}$ can be assessed objectively without consideration of the team process. Process performance measures, in contrast, are action-related aspects of performance embedded in the team processes. ${ }^{15}$ Process performance measures are often more easily accessible and less influenced by other variables than outcome performance measures because they refer to directly observable behaviours executed by the team during patient treatment (e.g. measuring task execution time, rating specific behaviours according to medical guidelines). ${ }^{25} 26$ 
In the infancy of team research in medicine, the main aim was to generate a general understanding of which team processes influenced performance in which way. After qualitative studies investigating which team processes might be relevant to clinical performance, ${ }^{27} 28$ quantitative studies were conducted to develop a clearer understanding of the impact of team processes on clinical performance. Studies investigated the association between team processes and either process performance ${ }^{72}$ or outcome performance measures. ${ }^{23}$ However, despite this improved understanding, it is still not clear how large the effect of these relationships is because in the majority of cases, no effect sizes are reported.

This systematic literature review aims to address this gap by analysing articles that investigate the relationship between team processes and clinical performance measures (i.e. process or outcome performance) and to report and compare the respective effect sizes. Furthermore, we will describe and discuss the different team processes and clinical performance measures used. This knowledge is needed to design targeted studies and effective interventions for patient care teams.

\section{Methods}

We conducted a literature search based on the recommendations of the PRISMA statement ${ }^{30}$ consulting the databases PubMed, Science Direct, PsycINFO, PSYNDEXplus Literature, and Audiovisual Media. Additionally, a meta-search with Google Scholar was conducted; of which, only the first 50 results were examined. The search term used was PATIENT SAFETY combined with TEAMWORK, COMMUNICATION, or LEADERSHIP. In addition, a hand search was conducted based on the references of the identified articles. The literature search was conducted in May 2012.

Figure 1 provides an overview of the inclusion criteria and the five-step selection procedure. We selected English articles published in journals between January 2001 and May 2012 investigating the relationship between team processes and clinical performance. We selected articles that showed or tried to demonstrate (i) a statistical relationship between a team process variable and clinical performance (process or outcome performance) or (ii) an improvement of clinical performance (process or outcome performance) through an intervention targeting team processes.

We included only articles with performance measures. We excluded articles which used self-report data because surveys or interviews about the teams' own perception of performance can contain a self-report bias ${ }^{31}$ and could potentially have distorted the results of this review. Intervention studies were only considered when targeting a team process behaviour (e.g. through training) and not implying structural changes (e.g. care pathways) ${ }^{32}$ at the same time, because this would preclude distinguishing between effects of the training $v s$ the structural change. We included studies using process or outcome performance measures. since our main focus was on factors influencing patient care, we excluded studies measuring team outcomes (e.g. job satisfaction, stress, burnout). ${ }^{5}$

Each step was performed independently by two reviewers (J.S. and Mariel Dardel). The agreement was between $90 \%$ and $94 \%$ in each step. Any disagreement in the selection process was resolved by extensive discussion.

\section{Rating of study quality}

In order to assess the methodological quality of the selected articles, we used a rating system based mainly on the one proposed by Buckley and colleagues. ${ }^{33}$ Since external validity is an important quality indicator, we replaced the single item by Buckley and colleagues with two items from a checklist by Downs and Black. ${ }^{34}$ For intervention studies, three items concerning the quality of the intervention were added from Downs and Black. The question of triangulation was not applied to the intervention studies because the focus was on the effect of the intervention and we did not expect authors of intervention studies to triangulate multiple methods. The complete list and a detailed description of quality indicators can be found in Supplementary Table S3.

Each indicator was scored as ' 0 ' (not fulfilled), '0.5' (partially fulfilled), ' 1 ' (complete), or 'not mentioned' (i.e. information not explicitly provided and thus unclear whether the criterion has been fulfilled or not). Quality ratings were performed by J.S. A random sample of five studies was rated by T.M. We achieved consistency of $91 \%$. Disagreements in the ratings were due to different interpretations of the descriptions in the articles and were resolved by discussion.

\section{Data extraction}

The following characteristics of the selected studies that were deemed most relevant were extracted, to evaluate the statistical relationships between team processes and clinical performance: team process behaviours, performance measures, participants, and results plus a description of the intervention in the case of intervention studies. Additionally, we calculated the effect size for every statistical processoutput relationship reported in the selected studies based on the data provided in the articles. This enabled us to determine not only if team processes are significantly related with clinical performance but also how large this effect is and if it is large enough to be relevant for practical implications. ${ }^{35}$ We report only significant and non-significant effects that were explicitly stated in the selected articles, although additional relationships may have been investigated but not reported.

\section{Results}

As can be seen from Figure 1, the initial search yielded 5383 articles. After excluding the irrelevant studies in stage 2, 887 articles remained. In stage 3, 784 studies were selected, of which 258 used quantitative methods and were retained for stage 4. After applying the final selection step, we identified 28 studies; of which, seven were intervention studies. Table 1 and Table 2 provide an overview of the relevant 


\begin{tabular}{|c|c|}
\hline \multicolumn{2}{|r|}{ Stage 1: Initial search } \\
\hline Limitations: & $\begin{array}{l}\text { Journal articles, published in English, between January } 2001 \text { and March 2012, } \\
\text { human subjects. }\end{array}$ \\
\hline Results: & 5383 articles \\
\hline \multicolumn{2}{|r|}{ Stage 2: Screening of title and abstract } \\
\hline Filter: & $\begin{array}{l}\text { Articles examined for relevance to teamwork, team coordination, leadership or } \\
\text { communication in a hospital setting. }\end{array}$ \\
\hline Results: & 887 articles \\
\hline \multicolumn{2}{|r|}{ Stage 3: Screening of title and abstract } \\
\hline Filter: & $\begin{array}{l}\text { Articles investigate teamwork, leadership or communication. Handover studies } \\
\text { and articles concerning communication with the patient or relatives were excluded. } \\
\text { Also articles investigating communication over a device (e.g. telemedicine) were } \\
\text { excluded. }\end{array}$ \\
\hline Results: & 784 articles \\
\hline \multicolumn{2}{|r|}{ Stage 4: Screening of title and abstract } \\
\hline Filter: & Qualitative studies, interview studies, reviews and reports are excluded. \\
\hline Results: & 258 articles \\
\hline \multicolumn{2}{|r|}{ Stage 5: Screening of title, abstract and full-text } \\
\hline Filter: & $\begin{array}{l}\text { Articles show (or try to show) } \\
\text { (i) a statistical relationship between a team process variable and clinical } \\
\text { performance (process or outcome performance) or } \\
\text { (ii) an improvement of a clinical performance variable (process or outcome } \\
\text { performance) through an intervention concerning team processes. }\end{array}$ \\
\hline Results: & 28 articles \\
\hline
\end{tabular}

Fig 1 Systematic literature search, selection procedure and inclusion criteria.

characteristics pertaining to all the articles included in this review.

\section{Team processes investigated and their measurement}

The selected studies examined various team processes: communication, ${ }^{23} 24$ 36-38 coordination,, ${ }^{24}$ 39-41 leadership,7 24314243 non-technical skills, ${ }^{29} 44-49$ team behaviour, ${ }^{42}$ team monitoring behaviour, ${ }^{50}$ and teamwork. ${ }^{23} 3651$ Six studies examined more than one team process behaviour. 232431364243

In reviewing the articles, we noted a high variability in the research approaches and measures used to study these team processes. As can be seen from Table 3, observational studies were most prominent. Most studies used video-based behaviour coding of data obtained in a simulator setting $(n=10)$. Of the nine studies conducted in a clinical setting, three used video-based and six used live behaviour coding. Only three studies used surveys to collect team process data.

At the measurement instruments level, we found that four of the seven studies examining non-technical skills used the Surgical NOTECHS system. ${ }^{29}$ 44-46 The other three systems used were the Behavioural Marker Risk Index (BMRI), ${ }^{47}$ the Anaesthetists' Non-Technical Skills (ANTS), ${ }^{49}$ and one specific behavioural marker system for neonatal resuscitation. ${ }^{48}$ Three of the six studies investigating communication used different observation systems ${ }^{31} 3638$ and the other three all used different questionnaires. ${ }^{23} 2437$ Three studies conceptualized the team processes under investigation as teamwork. Of these studies, one used the Safety Attitude Questionnaire (SAQ), ${ }^{23}$ one used a rating system for teamwork behaviour, ${ }^{51}$ and one study focused on events disrupting teamwork. ${ }^{36}$ Of the five studies investigating leadership processes, four conducted observations but used different observation systems $s^{31} 42 \quad 4352$ and one study used a survey. ${ }^{24}$ Of the four studies focusing on coordination, three $\mathrm{e}^{39-41}$ used the coding system of Manser and colleagues $^{53}$ and one assessed coordination using a survey. ${ }^{24}$

\section{Process and outcome measures of clinical performance}

Table 4 summarizes the 50 performance measures used in the 28 studies sorted into 41 process performance measures and nine outcome performance measures. Fourteen studies recorded deviations (i.e. errors, problems, or non-routine events during treatment) as a measure of process 
Table 1 Characteristics of studies reporting relationships between team process behaviour and process or outcome performance

\begin{tabular}{|c|c|c|c|c|c|c|c|}
\hline Study & $\begin{array}{l}\text { Team process behaviour I } \\
\text { research method and tool }\end{array}$ & $\begin{array}{l}\text { Performance measure I } \\
\text { method }\end{array}$ & Participants / setting & Results & Effect size* & $\begin{array}{l}\text { Quality } \\
\text { score } \\
(\max =12)\end{array}$ & $\begin{array}{l}\text { 'Not } \\
\text { mentioned'§ }\end{array}$ \\
\hline $\begin{array}{l}\text { Burtscher and } \\
\text { colleagues }^{39}\end{array}$ & $\begin{array}{l}\text { Team coordination / } \\
\text { behaviour coding of video } \\
\text { data } \rightarrow \text { coding system for } \\
\text { coordination }{ }^{53} \text { consisting } \\
\text { of } 33 \text { codes, which are } \\
\text { grouped into five main } \\
\text { categories: information } \\
\text { management, task } \\
\text { management, } \\
\text { coordination via work } \\
\text { environment, } \\
\text { metacoordinaton, and } \\
\text { other communication }\end{array}$ & $\begin{array}{l}\text { Clinical performance of the } \\
\text { anaesthesia induction / } \\
\text { checklist-based rating } \\
\text { system by experts }\end{array}$ & $\begin{array}{l}\text { Anaesthesia staff, } 19 \\
\text { anaesthetists, } 14 \\
\text { nurses, teams of } 2-4 \\
\text { persons / clinical setting } \\
\text { (22 videos of routine } \\
\text { anaesthesia inductions) }\end{array}$ & $\begin{array}{l}\text { High performing } \\
\text { teams show a more } \\
\text { pronounced } \\
\text { increase in task } \\
\text { management in } \\
\text { response to NRE in } \\
\text { contrast to low- } \\
\text { performing teams }\end{array}$ & $\begin{array}{l}\text { Low performing teams: } \bar{x}_{1} \approx \\
23 \% \dagger \text { (routine) to } \bar{x}_{2} \approx \\
29 \% \neq \text { (NRE) vs. high } \\
\text { performing teams } \bar{x}_{3} \approx \\
16 \% \dagger \text { (routine) to } \bar{x}_{4} \approx \\
36 \% \neq \text { (NRE) (relative } \\
\text { amount of time teams } \\
\text { spent on task } \\
\text { management); } \\
t(20)=-2.75, p<.05\end{array}$ & 10 & 1 \\
\hline $\begin{array}{l}\text { Burtscher and } \\
\text { colleagues }{ }^{40}\end{array}$ & $\begin{array}{l}\text { Adaptive coordination } \\
\text { while different phases of a } \\
\text { treatment / behaviour } \\
\text { coding of video data } \rightarrow \\
\text { coding system for } \\
\text { coordination }{ }^{53} \text { consisting } \\
\text { of } 33 \text { codes, which are } \\
\text { grouped into five main } \\
\text { categories: information } \\
\text { management, task } \\
\text { management, } \\
\text { coordination via work } \\
\text { environment, } \\
\text { metacoordinaton, and } \\
\text { other communication }\end{array}$ & $\begin{array}{l}\text { Decision latency / time } \\
\text { from the recognition of } \\
\text { the asystole until the } \\
\text { decision how to respond } \\
\text { to it } \\
\text { Execution latency / time } \\
\text { from deciding what to } \\
\text { do until restoration of } \\
\text { sinus rhythm) }\end{array}$ & $\begin{array}{l}15 \text { anaesthesia trainees, } \\
15 \text { anaesthesia nurses, } \\
\text { teams of } 2 \text { persons / } \\
\text { simulation (standard } \\
\text { anaesthesia induction) }\end{array}$ & $\begin{array}{l}\text { Negative association } \\
\text { between decision } \\
\text { latency and the } \\
\text { anaesthesia } \\
\text { trainees change in } \\
\text { information } \\
\text { management } \\
\text { No association } \\
\text { between other } \\
\text { coordination } \\
\text { aspects and } \\
\text { decision latency or } \\
\text { execution time }\end{array}$ & $r=-.49(p=.003)$ & 9 & 1 \\
\hline $\begin{array}{l}\text { Burtscher and } \\
\text { colleagues }^{50}\end{array}$ & $\begin{array}{l}\text { Team monitoring } \\
\text { behaviour / behaviour } \\
\text { coding of video data } \rightarrow \\
\text { coding each time a team } \\
\text { member was observing } \\
\text { the action of a teammate }\end{array}$ & $\begin{array}{l}\text { Clinical performance of the } \\
\text { anaesthesia induction / } \\
\text { checklist-based rating } \\
\text { system by experts }\end{array}$ & $\begin{array}{l}31 \text { anaesthesia resident, } \\
31 \text { anaesthesia nurses, } \\
\text { teams of } 2 \text { persons / } \\
\text { simulation (anaesthesia } \\
\text { induction) }\end{array}$ & $\begin{array}{l}\text { Negative association } \\
\text { between team } \\
\text { monitoring and } \\
\text { performance }\end{array}$ & $r=-.44(p=.02)$ & 10 & 1 \\
\hline $\begin{array}{l}\text { Carlson and } \\
\text { colleagues }\end{array}$ & $\begin{array}{l}\text { Leadership (LS) and team } \\
\text { behaviour / behaviour } \\
\text { coding of video data } \rightarrow \\
\text { global assessment of one } \\
\text { dominant style of } \\
\text { leadership (transactional } \\
\text { LS, flexible/dynamic team } \\
\text { LS, neither); rating }(0-4) \text { of } \\
\text { four team behaviour } \\
\text { categories (workload } \\
\text { management, } \\
\text { communication, } \\
\text { prioritizing and } \\
\text { reassessing priorities, } \\
\text { vigilance) }\end{array}$ & $\begin{array}{l}\text { Standard of care / expert } \\
\text { assessment in } \\
\text { consideration of } \\
\text { behavioural guidelines } \\
\text { (poor, marginal, } \\
\text { standard of care) }\end{array}$ & $\begin{array}{l}1133^{\text {rd }} \text { - year } \\
\text { undergraduate medical } \\
\text { students, teams of } 2-3 \\
\text { persons / simulation } \\
\text { (acute dyspnea) }\end{array}$ & $\begin{array}{l}\text { Pos. association of the } \\
\text { average team score } \\
\text { (mean of the four } \\
\text { dimensions) and } \\
\text { standard of care } \\
\text { No interrelation of LS } \\
\text { style and standard } \\
\text { of care }\end{array}$ & $r=.77(p<.0001)$ & 8 & 2 \\
\hline
\end{tabular}


Non-technical skills I behaviour coding of vide and live data $\rightarrow$ Surgical NOTECHS measurement framework
Problems / observation

traoperative based rating system by

experts

Operating time
42 paediatric and

teams / clinical setting

orthopaedic operations)

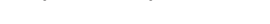

Catchpole and colleagues $^{73}$

Non-technical skills / live behaviour coding $\rightarrow$

Surgical NOTECHS

measurement framework

Operating time

Errors in surgical

48 surgical operation

26 laparoscopic

cholecystectomies, 22

carotid

endarterectomies)

Davenport and

colleagues $^{23}$

communication / survey

$\rightarrow$ Safety attitudes

questionnaire (SAQ) days after the operation) surgery from 44

I data from the National surgery from 44 performance / checklist-

orthopaedic operation

(paediatric and

Other procedural problems

and errors / observation

teams / clinical setting

Teams with effective

teamwork have:

Fewer minor problems $\dagger \bar{x}_{1} \approx 7.3 \dagger$ (effective teams) per operation vs. $\bar{x}_{2} \approx 11.1 \dagger$ (ineffective

Higher intraoperative

performance teams) vs. $\bar{x}_{4} \approx 95.5 \% \dagger$

$\bar{x}_{3} \approx 93.3 \%+$ (effective

$$
\text { (ineffective teams) }
$$

Shorter operating

times than teams with less effective $\bar{x}_{5} \approx 195$ min. $\dagger$ (effective teamwork (ineffective teams) $t=2.25$ $p=.03$

Association between situation

$\dagger(F(2,42)=7.93, p=0.001)$

awareness and

technique

LS \& Management

and operating time

Association between

LS \& Management

score of the nurse

and other

procedural

problems and

errors

No association

between other

NOTECHS

dimensions and

any performance

measure

Mortality (patient death in 6083 staff members of Significant negative

or out of the hospital 30 general and vascular correlation between

morbidity and

1 data from the National Veterans Affairs and 8 Surgical Quality academic medical

Positive

communication of (NSQIP)

Morbidity (patient having 1

or more postoperative

complications up to 30

days after operation)

centres / clinical setting surgical service

care providers with attending doctors

Positive

$(F(2,42)=3.32, p=0.046)$

$\dagger(F(5,1)=3.96, p=0.027)$

NS

communication of

care providers with

residents

No interrelation of

teamwork and

mortality

No interrelation of

teamwork and

morbidity

$$
r=-.38(p<0.01)
$$

$$
r=-.25(p<0.08)
$$


Table 1 Continued

\begin{tabular}{|c|c|c|c|c|c|c|c|}
\hline Study & $\begin{array}{l}\text { Team process behaviour I } \\
\text { research method and tool }\end{array}$ & $\begin{array}{l}\text { Performance measure I } \\
\text { method }\end{array}$ & Participants / setting & Results & Effect size ${ }^{*}$ & $\begin{array}{l}\text { Quality } \\
\text { score } \\
(\max =12)\end{array}$ & $\begin{array}{l}\text { ‘Not } \\
\text { mentioned'§ }\end{array}$ \\
\hline $\begin{array}{l}\text { ElBardissi and } \\
\text { colleagues }^{36}\end{array}$ & $\begin{array}{l}\text { Teamwork and } \\
\text { communication } \\
\text { disruptions / live behaviour } \\
\text { coding } \rightarrow \text { any occurrence } \\
\text { concerning teamwork } \\
\text { /communication that } \\
\text { disrupted the flow of the } \\
\text { operation }\end{array}$ & $\begin{array}{l}\text { Errors (events failed its } \\
\text { intended outcome) / } \\
\text { observation }\end{array}$ & $\begin{array}{l}5 \text { surgeons / clinical } \\
\text { setting ( } 31 \text { cardiac } \\
\text { surgical operations) }\end{array}$ & $\begin{array}{l}\text { Positive association } \\
\text { between teamwork } \\
\text { disruptions and } \\
\text { surgical errors }\end{array}$ & $r=.67(p<0.001)$ & 11 & 0 \\
\hline $\begin{array}{l}\text { Künzle and } \\
\text { colleagues }^{7}\end{array}$ & $\begin{array}{l}\text { Leadership / behaviour } \\
\text { coding of video data } \\
\text { (structuring LS, content } \\
\text { oriented LS and total } \\
\text { amount of LS) }\end{array}$ & Execution time & $\begin{array}{l}12 \text { anaesthesia teams / } \\
\text { simulation (anaesthesia } \\
\text { induction) }\end{array}$ & $\begin{array}{l}\text { Negative association } \\
\text { between execution } \\
\text { time during routine } \\
\text { and highly } \\
\text { standardized phases } \\
\text { and } \\
\text { structuring LS and } \\
\text { content oriented LS } \\
\quad \text { and } \\
\text { total amount of LS } \\
\text { No significant } \\
\text { association } \\
\text { between LS and } \\
\text { execution time } \\
\text { during a nonroutine } \\
\text { event }\end{array}$ & $\begin{array}{l}r=-.59(p<.05) \\
r=-.52(p<.10) \\
r=-.56(p<.05) \\
\text { NS }\end{array}$ & 9.5 & 1 \\
\hline $\begin{array}{l}\text { Manojlovich and } \\
\text { colleagues }^{37}\end{array}$ & $\begin{array}{l}\text { Communication / survey } \\
\rightarrow \text { ICU Nurse-Physician } \\
\text { Questionnaire ( } 4 \text { scales: } \\
\text { openness, accuracy, } \\
\text { timeliness and } \\
\text { understanding) }\end{array}$ & $\begin{array}{l}\text { Ventilator-associated } \\
\text { pneumonia / data from } \\
\text { the hospital database } \\
\text { Bloodstream infections / } \\
\text { data from the hospital } \\
\text { database } \\
\text { Pressure ulcers / data from } \\
\text { the hospital database }\end{array}$ & $\begin{array}{l}462 \text { nurses from } 25 \text { ICUs } \\
\text { / clinical setting }\end{array}$ & $\begin{array}{l}\text { Negative association } \\
\text { between } \\
\text { timeliness and } \\
\text { pressure ulcers. } \\
\text { No significant } \\
\text { association } \\
\text { between overall } \\
\text { communication or } \\
\text { other subscales and } \\
\text { outcome variables }\end{array}$ & $\begin{array}{l}r=-.38(p=.06) \\
\text { NS }\end{array}$ & 9.5 & 1 \\
\hline $\begin{array}{l}\text { Manser and } \\
\text { colleagues }^{41}\end{array}$ & $\begin{array}{l}\text { Team coordination / } \\
\text { behaviour coding of video } \\
\text { data } \rightarrow \text { coding system for } \\
\text { coordination }{ }^{53} \text { consisting } \\
\text { of } 33 \text { codes, which are } \\
\text { grouped into five main } \\
\text { categories: information } \\
\text { management, task } \\
\text { management, } \\
\text { coordination via work } \\
\text { environment, } \\
\text { metacoordinaton, and } \\
\text { other communication }\end{array}$ & $\begin{array}{l}\text { Clinical performance / } \\
\text { checklist-based rating } \\
\text { system by experts }\end{array}$ & $\begin{array}{l}48 \text { first year students, } \\
\text { teams of } 2 \text { persons / } \\
\text { simulation (malignant } \\
\text { hyperthermia) }\end{array}$ & $\begin{array}{l}\text { Positive association } \\
\text { between task } \\
\text { distribution and } \\
\text { performance }\end{array}$ & $r=-.466(p<0.01)$ & 10 & 1 \\
\hline
\end{tabular}


Marsch and colleagues $^{43}$

distribution and

information transfer /

behaviour coding of video

data if the specific

behaviour is present or not
Clinical performance / time based scoring system fo critical treatment steps

nurses and 1 physician show

each / simulation

(cardiopulmonary

resuscitation)
Mazzocco and

colleagues $^{47}$

Mishra and colleagues $^{29}$

Non-technical skills / live behaviour coding $\rightarrow$

Surgical NOTECHS

measurement framework

$\begin{array}{ll}\text { Pollack and } & \text { Leadership, } \\ \text { colleagues }^{24} & \begin{array}{l}\text { communication and } \\ \text { coordination / survey } \rightarrow \\ \text { organizational } \\ \text { assessment tool }\end{array}\end{array}$

Schraagen ${ }^{74}$ technical skills / live haviour coding

according to the behaviour marker risk index (BMRI)
Mortality

Bronchopulmonary dysplasia

Periventricular

intraventricular haemorrhage or leukomalacia

Retinopathy of prematurity

Length of stay

All outcomes were

collected from clinical records

Non-technical skills / live

behaviour coding $\rightarrow$

Observation

Operating time

30-day postsurgical

outcome

(uncomplicated, minor

complication, majo

complications or death)
6/6 (successful teams showed task distribution) vs. 4/10 (failing teams showed task distribution), odds ratio can't be calculated

\section{more LS behaviour than failing teams.}

\section{$O R=8$ (successful teams} show 8 times more likely $S$ behaviour than failing

No significant difference in information transfer

8.5

NS

130 physicians, nurses, Patients were more $\quad O R=4.82$ (corrected for

(ikely to experience preoperative physical fitness)

death or a major

complication when

there were less

teamwork

behaviours

setting (300 s

cases)

Surgeons, anaesthetists, Negative association

nurses / clinical setting

$\rho=-.718(p<.001)$

awareness of

surgeons and

operations)

Nurses, physicians and Positive association

respiratory therapists of between leadership

and PIVH/PVL

8 neonatal intensive
care units / clinical

between

coordination and

$\mathrm{PIVH} / \mathrm{PVL}$

No significant results

for communication

and the other

outcome measures

Paediatric cardiac

Positive association

NS

surgical teams / clinical

between teamwork

and operating

times

No association

between teamwork

and non routine

event

No association

between teamwork

and outcome 
Westli and

colleagues $^{49}$

Non-technical skills /

behaviour coding of video

data $\rightarrow$ ANTS system

(revised)
-Performance score / checklist-based rating system by experts

-Medical Management / overall rating from 1-5
27 trauma teams

consisting of 1 surg

anaesthesiologist, 2

nurses, 1 radiographer /

simulation

(resuscitation)
Negative association

between

Medical Management and poor

coordination

Performance score

and supporting

behaviour

Positive association

between Medical

Management and

information

exchange

No correlation

between

performance score

and

coordination

poor Coordination

use of authority

capabiliteis NS

oor supporting

behaviour

No correlation

between Medical

Management and

coordination

use of authority

supporting behaviour NS

poor supporting

oor supporting

${ }^{*} r$, $\rho$ and $\hat{w}^{2}$ effect sizes are interpreted as follows: $r$ or $\rho=.10$ small effect; $r$ or $\rho=.30$. medium effect; $r$ or $\rho=.50$ large effect ${ }^{62,75} ; \hat{w}^{2}=0.01$ small effect, $\hat{w}^{2}=0.09$ medium effect, $\hat{w}^{2}=0.25$ large effect ${ }^{73}$ † The required information to calculate the effect sizes are not available. If available the absolute sizes are indicated instead.

$\ddagger$ Means are assessed out of figures. The exact means are not mentioned in the text.

- Kendall's Tau $(\tau)$ was transformed into $r$ according to Walker $^{74}$

$\S$ 'Not mentioned' means it was unclear if something has been done or not based on the information provided in the article. NS, Not Significance. 
Table 2 Characteristics of team process behaviour interventions and their impact on performance. Team process measures used in the intervention studies are not listed here because for these studies, the focus is on the effect of the intervention on performance and not on the process. ${ }^{*}$ The required information to calculate the effect sizes was not available. The absolute sizes are indicated instead. ${ }^{\dagger} \hat{w}^{2}$ effect sizes are interpreted as follows: $\hat{w}^{2} \geq 0.01$ small, $\hat{w}^{2} \geq 0.09$ medium, and $\hat{w}^{2} \geq 0.25$ large; ${ }^{71}$ Cohen's $d$ effect sizes are interpreted as follows: $d \geq 0.20$ small, $d \geq 0.50$ medium, and $d \geq 0.80$ large. ${ }^{71} \neq$ Not mentioned' means it was unclear if something has been done or not based on the information provided in the article

\begin{tabular}{|c|c|c|c|c|c|c|c|}
\hline Study & $\begin{array}{l}\text { Intervention/design/team } \\
\text { process measure* }\end{array}$ & $\begin{array}{l}\text { Performance measure/ } \\
\text { method }\end{array}$ & Participants & Results & Effect size $^{\dagger}$ & $\begin{array}{l}\text { Quality } \\
\text { score } \\
\text { ( } \max =14)\end{array}$ & $\begin{array}{l}\text { 'Not } \\
\text { mentioned" }\end{array}$ \\
\hline $\begin{array}{l}\text { Fernandez } \\
\text { Castelao and } \\
\text { colleagues }^{60}\end{array}$ & $\begin{array}{l}\text { Video based crew resource } \\
\text { management training/quasi- } \\
\text { experimental control group } \\
\text { post-test design/no team } \\
\text { process measure }\end{array}$ & $\begin{array}{l}\text { No-flow time (time with no } \\
\text { chest compression) }\end{array}$ & $\begin{array}{l}\text { Four-person medical } \\
\text { student teams, } 26 \text { teams in } \\
\text { the experimental group, } 18 \\
\text { teams in the control group }\end{array}$ & $\begin{array}{l}\text { Less no flow time } \\
\text { in the post- } \\
\text { intervention } \\
\text { group } \\
\text { comparing } \\
\text { with the } \\
\text { control group }\end{array}$ & $\begin{array}{l}\bar{x}_{1}=36.3 \% \\
(\text { control) vs } \\
\bar{x}_{2}=31.4 \\
(\text { experimental) } \\
(P=0.014)^{*}\end{array}$ & 11 & 0 \\
\hline $\begin{array}{l}\text { Kalisch and } \\
\text { colleagues }^{54}\end{array}$ & $\begin{array}{l}\text { Staff teamwork and } \\
\text { engagement enhancement } \\
\text { intervention/quasi- } \\
\text { experimental uncontrolled pre- } \\
\text { test-post-test design/post- } \\
\text { interview about teamwork }\end{array}$ & $\begin{array}{l}\text { Fall rates per } 1000 \text { patient } \\
\text { days/information from } \\
\text { patient report }\end{array}$ & $\begin{array}{l}49 \text { nurses, six unit } \\
\text { secretaries of a community } \\
\text { hospital }\end{array}$ & $\begin{array}{l}\text { Patient fall rates } \\
\text { decreased after } \\
\text { the } \\
\text { intervention }\end{array}$ & $\begin{array}{l}\bar{x}_{1}=7.73 \text { to } \\
\bar{x}_{2}=2.99 \text { falls } \\
\text { per } 1000 \text { patient } \\
\text { days }(t=3.98 \\
P<0.001)^{*}\end{array}$ & 9 & 2 \\
\hline $\begin{array}{l}\text { McCulloch } \\
\text { and } \\
\text { colleagues }^{55}\end{array}$ & $\begin{array}{l}\text { Intervention based on principles } \\
\text { of civil aviation crew resource } \\
\text { management/quasi- } \\
\text { experimental uncontrolled pre- } \\
\text { test-post-test design/NOTECHS } \\
\text { and SAQ teamwork climate } \\
\text { score }\end{array}$ & $\begin{array}{l}\text { Operating technical errors/ } \\
\text { observation } \\
\text { Operating time } \\
\text { Length of stay }\end{array}$ & $\begin{array}{l}\text { Surgeons, andesthetists, } \\
\text { nurses performing } 48 \\
\text { operations in the pre- } \\
\text { intervention group and } 55 \\
\text { operations in the post- } \\
\text { intervention group }\end{array}$ & $\begin{array}{l}\text { Less operating } \\
\text { technical errors } \\
\text { after the } \\
\text { intervention } \\
\text { No reduction in } \\
\text { operating time } \\
\text { No reduction in } \\
\text { length of stay }\end{array}$ & $d=0.63(P=0.009)$ & 10.5 & 0 \\
\hline $\begin{array}{l}\text { Morey and } \\
\text { colleagues }^{57}\end{array}$ & $\begin{array}{l}\text { Emergency Team Coordination } \\
\text { Course (ETCC)/quasi- } \\
\text { experimental control group } \\
\text { design with one pre- and two } \\
\text { post-tests/Behaviour Anchored } \\
\text { Rating Scales (BARS) }\end{array}$ & Errors/observation & $\begin{array}{l}\text { Physicians, nurses, and } \\
\text { technicians of six } \\
\text { emergency departments } \\
\text { (EDs) in the experimental } \\
\text { group ( } n=684 \text { ) and three } \\
\text { EDs in the control group } \\
(n=374)\end{array}$ & $\begin{array}{l}\text { Decrease in the } \\
\text { clinical error } \\
\text { rate in the } \\
\text { post- } \\
\text { intervention } \\
\text { group } \\
\text { No significant } \\
\text { difference } \\
\text { between the } \\
\text { experimental } \\
\text { and control } \\
\text { group }\end{array}$ & $d=1.93(P=0.039)$ & 12 & 1 \\
\hline $\begin{array}{l}\text { Nielsen and } \\
\text { colleagues }^{58}\end{array}$ & $\begin{array}{l}\text { MedTeams Labor and Delivery } \\
\text { Team Coordination Course } \\
\text { based on crew resource } \\
\text { management trainings/cluster- } \\
\text { randomized control group } \\
\text { design with no pre-test/no team } \\
\text { process measure }\end{array}$ & $\begin{array}{l}\text { Adverse maternal Outcome } \\
\text { Index (number of patients } \\
\text { with one or more adverse } \\
\text { outcomes divided by the } \\
\text { total number of } \\
\text { deliveries)/information } \\
\text { from patient report }\end{array}$ & $\begin{array}{l}\text { Obstetrician, } \\
\text { anaesthesiologist, and } \\
\text { nurses of seven hospitals } \\
\text { (obstetrics) in the } \\
\text { experimental group } \\
\text { ( } n=1307 \text { ) and eight } \\
\text { hospitals in the control } \\
\text { group }\end{array}$ & $\begin{array}{l}\text { Significant } \\
\text { reduction in } \\
\text { Caesarean } \\
\text { delivery } \\
\text { decision to } \\
\text { incision }\end{array}$ & $\begin{array}{l}\bar{x}_{1}=33.3 \mathrm{~min} \\
\text { (control) vs } \\
\bar{x}_{2}=21.2 \\
(\text { experimental) } \\
(P=0.039)^{*}\end{array}$ & 12 & 0 \\
\hline
\end{tabular}




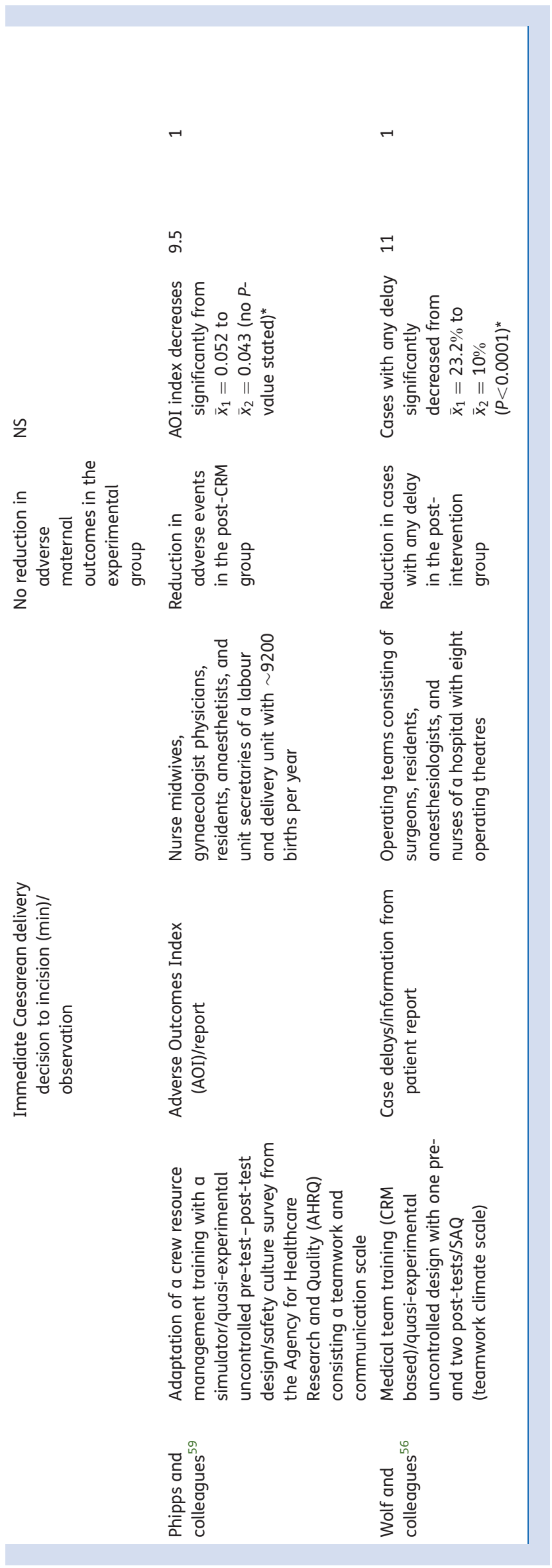

Table 3 Methods and research settings for studying the team process-performance relationship

\begin{tabular}{lll}
\hline Methods/settings & $\begin{array}{l}\text { Number } \\
\text { of articles }\end{array}$ & $\begin{array}{l}\text { Study reference } \\
\text { number }\end{array}$ \\
\hline $\begin{array}{l}\text { Live observation/clinical } \\
\text { setting }\end{array}$ & 6 & $29,36,44,47,45,72$ \\
$\begin{array}{l}\text { Video-based } \\
\text { observation/clinical } \\
\text { setting }\end{array}$ & 3 & $39,44,48$ \\
$\begin{array}{l}\text { Video-based } \\
\text { observation/simulation } \\
\text { Survey/clinical setting }\end{array}$ & 3 & $7,31,38,40-43,49-51$ \\
\hline & 10 & $23,24,37$ \\
\hline
\end{tabular}

performance. Performance checklists based on clinical guidelines were the next frequently used performance measure $(n=10)$ followed by the time until a specific treatment is conducted $(n=7)$. The outcome performance measure used most frequently was complications after treatment $(n=4)$.

\section{Effects of team processes on performance in the non-intervention studies}

In total, the 21 studies reported 66 relationships of a team process variable with a performance variable. Forty of these effects were significant and 26 were non-significant. Thirteen of the 21 non-intervention studies calculated correlations to investigate this relationship. More than one performance measure was used by 15 studies and 12 of these reported both non-significant and significant effects. Only six studies investigated just one effect and assessed only one performance measure. All of them were significant.

No study explicitly reported effect sizes. The effect sizes calculated are shown in Table 1 and Table 2. They range from very high $(r=0.77)^{42}$ to small $(\rho=-0.02) .^{48}$ Only one study reported a small effect, ${ }^{48}$ while all the others described effects considered as large or medium.

\section{Interventions targeting team process behaviours}

The interventions were carried out in community hospitals, ${ }^{54}$ operating theatres, ${ }^{55} 56$ emergency departments, ${ }^{57}$ and labour and delivery units. ${ }^{58} 59$ Five of the seven intervention studies used training explicitly based on crew resource management (CRM) principles, ${ }^{55} 56$ 58-60 while the other two studies included some CRM elements such as an introduction to teamwork and non-technical skills. According to the brief descriptions in the articles, it appears that all interventions were of similar content. Typical topics discussed in the training were principles of teamwork and human factors, situation awareness, improvement of team skills, communication, and leadership. The duration of the training ranged from 1 to 2 days and included methods such as theoretical lectures on CRM principles, video analysis, and role-playing. Unfortunately, an exact comparison of the interventions is not possible due to the limited descriptions of the training provided in the articles. Table 2 summarizes the effects of the seven interventions, all 
Table 4 Performance measures used. *If multiple performance measures are used in one article, the study is mentioned several times. NREs, non-routine events

\begin{tabular}{lll}
\hline Performances measures used & $\begin{array}{l}\text { Total number of performance } \\
\text { measures used }\end{array}$ & Study reference number* \\
\hline Process performance measure & & $24,24,24,29,36,37,37,37,44,44,55,57,45,72$ \\
Deviations (errors, problems, NREs during the treatment) & 14 & 56 \\
Case delays & 1 & 24,55 \\
Length of stay & 2 & $7,44,55,45,72$ \\
Operating time & 5 & 31,60 \\
Percentage of time the patient receives a specific treatment & 2 & $40,40,43,51,51,51,58$ \\
Time until a specific treatment is conducted & 7 & $31,39,41,42,44,48,49,49,50,51$ \\
Performance checklists & 10 & \\
Outcome performance measures & & $47,58,59,72$ \\
Complications after operation & 4 & 38 \\
Diagnostic accuracy & 1 & 54 \\
Fall rates & 1 & 23 \\
Morbidity & 1 & 23,24 \\
Mortality & 2 & \\
\hline
\end{tabular}

indicating significant improvements of performance after the intervention. The intervention studies reported 11 effects on a performance measure; of which, seven were significant. Three studies assessed more than one performance measure. Only two studies indicated all the information to calculate the effect size and they reported one medium ${ }^{55}$ and one large effect. ${ }^{57}$

\section{Quality of the selected studies}

A complete list of the quality ratings for every article can be found in the Supplementary Table S1 and Supplementary Table S2. The study quality ratings ranged from 9 to 12 points out of 14 for the intervention studies and from 8 to 11 out of 12 points for the other studies. Overall, data collection methods were found to be reliable and valid to answer the specific research questions. Two common problems were the poor discussion of potential confounding factors and the use of a single data collection method instead of strengthening the results through triangulation.

All non-intervention studies were prospective. In general, research questions were clearly stated, methods well described, analyses were appropriate, and the conclusions clearly justified by the results.

All intervention studies used quasi-experimental or clustered designs. Only three of the seven intervention studies applied a control group design, while the other four were pre-test-post-test studies. Two studies included a follow-up post-test to investigate long-term effects. All intervention studies provided unspecific descriptions of the conducted interventions limiting their reproducibility.

\section{Other study characteristics}

The studies included participants of various professions examining teams consisting of anaesthetists, nurses, medical students, paediatricians, surgeons, operating theatre technicians, and midwives. In four studies, the participants were uniprofessional. ${ }^{37} 384142$

\section{Discussion}

The aim of our systematic literature review was to consolidate the statistical evidence for the effects of team processes on clinical performance in patient care teams. Furthermore, we provide an overview of all team process and performance measures used in these studies that will inform future research in this field regarding the strength and weaknesses of current measures and necessary developments.

Focusing on the process-performance relationship, this review found that significant progress has been made in recent years. Most studies report strong effects indicating that team processes are significantly influencing clinical performance. However, we identified areas for improvement with regard to defining and measuring both team processes and clinical performance. Our systematic analysis of study quality also points at possible improvements in both study design and reporting.

Most studies did not refer to a conceptual framework. They sometimes used vague definitions of the two concepts 'team process behaviours' and 'performance' and a broad range of measurement approaches was also seen. An appropriate scientific definition and explicit reference to a common conceptual framework are prerequisites for comparing studies that investigate a broad spectrum of team process behaviours. Such a framework aids in study design and interpretation of results. Although the IPO model is rather simple, it is widely accepted and has proven useful in various teamwork settings. The IPO model facilitates the research process by providing a clear structure of potential 
relationships upon which to focus (e.g. the impact of team mental models as an input on team process behaviours such as decision-making or the relationship between leadership processes within the team and subjective outcomes such as staff well-being).

While more complex models such as the input-throughput-output model of team adaptation of Burke and colleagues $^{61}$ have been developed to reflect the complexity of teamwork, these models are often too complex for isolating research questions that can be tested in an actual work setting. We have to strive for a balance between complexity and feasibility for these models to be useful in guiding team research in healthcare and in conceptually clarifying the relevant inputs, team process behaviours, and outcomes.

Most studies measuring team process behaviours have used observational methods. This is a more time-consuming method than questionnaire-based designs, but generally, observational methods are the most appropriate way to describe and measure processes. It avoids the problems of subjectivity and recall bias inherent in questionnaire-based designs, ${ }^{62}{ }^{63}$ especially in stressful situations. While questionnaire-based assessment provides a more general picture of team members' perceptions of team processes, observation methods capture the actions actually performed by the team members.

Moreover, to assure a valid assessment of team processes, observation systems should be as holistic and detailed as possible instead of focusing on a single behavioural facet. The observation system should allow for categorizing all behaviours performed by the team to investigate the interactions between different team behaviours and their relative contribution to the outcome.

The two observation systems used most frequently in the selected studies was the observation method of Manser and colleagues $^{53}$ and the behavioural marker system Surgical NOTECHS. ${ }^{44}$ The system of Manser and colleagues assesses different aspects of team coordination including information management, task management, coordination via work environment, and others. The NOTECHS system includes behavioural dimensions such as leadership, teamwork, problemsolving, situation awareness, etc. The difference between these two systems is that the former is descriptive, that is, it objectively records actions of the team continuously without any evaluation. Other authors also use descriptive, non-evaluative systems. ${ }^{31} 384352$ In the Surgical NOTECHS system, the target behaviours are rated on a scale from 1 to 4 for a defined teamwork episode (e.g. anaesthesia induction). This evaluative component may artificially increase the relationship with performance ratings, while descriptive observation systems provide more objective data on the team process. Thus, it is critical to define performance measures that are truly independent of the team process measures.

The ultimate outcome of high performance in healthcare should be patient safety. As patient safety itself is difficult to measure and to relate to specific team process, various proxy measures have been used. The studies included in this review used many different measures to assess clinical performance that can be grouped into process performance measures and outcome performance measures.

Outcome performance measures are related to the result of the actions and depend on more than just individuals' behaviour. ${ }^{21}$ For example, it is known from resuscitation that the duration of a patient's arrest, the primary arrhythmia, and patient age are better predictors for survival than the actual performance of the clinicians performing the resuscitation. ${ }^{64}$ In clinical settings, it is impossible to take in to account all the factors potentially influencing performance, but there are ways to control some of them. For example, the ASA patient classification index has been used to classify patients' risk for complications taking into account the history of the patient ${ }^{47}$ and the score for neonatal acute physiology (SNAP) has been used to assess the possibility of complications accounting for the newborn's physiology. ${ }^{24}$ Another way to control or balance for confounders are large sample sizes that are often not feasible for very detailed, resource-intensive analyses of team processes and sometimes difficult to obtain in healthcare; especially in field studies requiring a high number of specific, comparable cases performed by care providers with predefined experience levels. In addition, ethical issues sometimes limit the spectrum of cases that can be studied using live observation in clinical settings.

Besides outcome performance measures, the processes leading to this outcome are also good indicators for performance (e.g. timely start of the correct treatment for the patient). These process performance measures refer to what an individual does in a specific work situation and are therefore less influenced by other factors. ${ }^{21}$ Process performance can be assessed in almost every setting. During simulation, where it is hardly possible to assess patient-related outcomes, process performance measures are preferable. Performance checklists, for example, that take into account the most important actions for a specific treatment and evaluate those across the whole process provide a valid and reliable method to assess process performance if developed systematically. This includes a theoretical foundation and an integration of official guidelines and experiences of several experts ${ }^{65}$ (e.g. through a Delphi process as, for example, done by Burtscher and colleagues). ${ }^{3966}$

For intervention studies, the results of our review showed that training targeting team process behaviours do influence various outcomes. All the interventions focused exclusively on outcome performance measures. Therefore, one can only assume that the interventions influenced the team processes, which in turn led to better outcomes. This assumption will require further empirical testing to improve our understanding of the mechanisms through which the improvements have been achieved. Unfortunately, no effect sizes could be calculated for most studies, so it is difficult to determine how strong these effects really are. Also, each study referred to a different intervention, none of which was sufficiently described to be reproducible (for a discussion of this issue, see also Buljac-Samardzic and colleagues). ${ }^{67}$ 


\section{Limitations}

Several limitations of this systematic review have to be taken into account when interpreting the results. We focused only on English, peer-reviewed articles and did not include books or grey literature, so we may have missed relevant publications. Owing to the difficulties with publishing non-significant results, ${ }^{68}$ there may be other studies which found no effect of team process behaviour or interventions on performance which we could not access.

In this review, we listed the team processes as they appear in the selected articles. However, if two studies used the same term, this does not necessarily mean they also referred to the same definition of this team process. Furthermore, we focused exclusively on the relationship between team processes and outputs. However, we acknowledge that team processes are not independent of input factors. Specific input factors could neutralize the relationship between processes and outputs. For example, Burtscher and colleagues ${ }^{50}$ found a relationship between team monitoring behaviour and performance only when the team members had a shared mental model of the task.

\section{Future research}

This review identified some gaps in the literature on the relationship between team process behaviours and clinical performance.

Since most studies focus on acute patient care, more research needs to be done in other domains of healthcare such as long-term care. Also, only two studies included in this review conducted a follow-up post-test to check if the interventions also had a long-term effect. Thus, studies investigating team processes using a longitudinal design are needed; especially for intervention studies.

In comparison with the sizable literature on the importance of team process behaviour in healthcare, little research has actually investigated the statistical effects on process or outcome performance. To achieve this, valid process performance measures are required and will have to be developed systematically. That is, the relationship of process performance (e.g. checklist-based assessments) and outcomes has to be tested in controlled clinical studies to assure their validity and reliability for assessing performance in clinical and simulated settings.

Of course, there is no single best performance measure. In occupational psychology, it is widely accepted that performance is a multidimensional construct. ${ }^{15} 21$ Thus, to get an accurate picture of performance, future studies should use multiple process performance measures or even combinations of process and outcome performance measures. ${ }^{24} 374445$

To further our understanding of specific team processes such as coordination or leadership studies using the same observation systems and performance measures are needed. We gave a brief overview including pros and cons of different measurement methods and future research should take these considerations into account. This will result in more conceptual and methodological consistency and more definitive findings about the effects of team process behaviours on performance (e.g. supported by meta-analyses).

Our results suggest that team processes in general are clinically relevant because they have an effect on patient outcomes. A large effect size is an indicator for high clinical relevance; however, they are not necessarily linked. ${ }^{69}$ For a more precise assessment of clinical relevance, future research should include other factors than statistical results as well.

Some studies included in this review show rather small or no correlations between team processes and performance. ${ }^{48} 49$ It is not certain if this is due to unclear or inconsistent definitions of the constructs, validity issues, or confounders. However, we are sure that future research will help to explain and clarify these contradictory results with (i) clear and consistent definitions of the team processes investigated and (ii) more complete descriptions of the mechanisms linking specific team processes to specific performance measures that is embedded in a theoretical framework. Lingard and colleagues ${ }^{70}$ illustrate how this could be done using the example of communication patterns related to collaborative work processes and patient safety. In this way, future research will deliver a more accurate picture of the relationship between team processes and performance. With this knowledge, we will be able to design more effective and successful team interventions and implementation strategies which will help to improve patient safety.

\section{Supplementary material}

Supplementary material is available at British Journal of Anaesthesia online.

\section{Acknowledgements}

We are grateful to Mariel Dardel for screening the literature and her help in the selection process of relevant articles.

\section{Declaration of interest}

None declared.

\section{Funding}

This work was supported by the Swiss National Science Foundation (grant number, PPOOP1_128616).

\section{References}

1 Manser T. Teamwork and patient safety in dynamic domains of healthcare: a review of the literature. Acta Anaesthesiol Scand 2009; 53: 143-51

2 Manojlovich M, DeCicco B. Healthy work environments, nursephysician communication, and patients outcomes. Am J Crit Care 2007; 16: 536-43

3 Kohn LT, Corrigan J, Donaldson MS. To Err Is Human: Building a Safer Health System. Washington, DC: National Academy Press, 1999

4 Salas E, Rosen MA, King H. Managing teams managing crises: principles of teamwork to improve patient safety in the emergency room and beyond. Theor Issues Ergon Sci 2007; 8: 381-94 
5 Reader TW, Flin R, Mearns K, Cuthbertson BH. Developing a team performance framework for the intensive care unit. Crit Care Med 2009; 37: 1787-93

6 Martin JS, Ummenhofer W, Manser T, Spirig R. Interprofessional collaboration among nurses and physicians: making a difference in patient outcome. Swiss Med Wkly 2010; 140: w13062

7 Künzle B, Kolbe M, Grote G. Ensuring patient safety through effective leadership behaviour: a literature review. Safety Sci 2010; 48: 1-17

8 Rutherford J, Flin R, Mitchell L. Non-technical skills of anaesthetic assistants in the perioperative period: a literature review. $\mathrm{Br} J$ Anaesth 2012; 109: 27-31

9 McGrath JE. Social Psychology: A Brief Introduction. Holt, New York: Rinehart and Winston, 1964

10 Gladstein DL. Groups in context: a model of task group effectiveness. Adm Sci Quart 1984; 29: 499-517

11 Ilgen DR, Hollenbeck JR, Johnson M, Jundt D. Teams in organizations: from input-process-output models to IMOI models. Annu Rev Psychol 2005; 56: 517-43

12 Hackman JR, Morris CG. Group tasks, group interaction process, and group performance effectiveness: a review and proposed integration. In: Berkowitz L, ed. Advances in Experimental Social Psychology. New York: Academic Press, 1975; 45-99

13 Hackman JR. The design of work teams. In: Lorsch JW, ed. Handbook of Organizational Behavior. Englewood Cliffs, NJ: PrenticeHall, 1987; 315-42

14 Jarboe S. A comparison of input-output, process-output, and input-process-output models of small group problem-solving effectiveness. Commun Monogr 1988; 55: 121-42

15 Tschan F, Semmer N, Vetterli M, Gurtner A, Hunziker S, Marsch SU. Developing observational categories for group process research based on task and coordination requirement analysis: examples from research on medical emergency-driven teams. In: Boos $M$, Kolbe M, Kappeler P, Ellwart T, eds. Coordination in Human and Primate Groups. Berlin: Springer, 2011; 93-115

16 Mathieu JE, Heffner TS, Goodwin GF, Salas E, Cannon-Bowers JA. The influence of shared mental models on team process and performance. J Appl Psychol 2000; 85: 273-83

17 Flin R. Identifying and training non-technical skills for teams in acute medicine. Qual Saf Health Care 2004; 13: i80-4

18 Campion MA, Medsker GJ, Higgs AC. Relations between work group characteristics and effectiveness: implications for designing effective work groups. Person Psychol 1993; 46: 823-50

19 Marks MA, Mathieu JE, Zaccaro S. A temporally based framework and taxonomy of team processes. Acad Manage Rev 2001; 26: 356-76

20 Anderson N, Ones DS, Sinangil HK, Viswesvaran C. Handbook of Industrial, Work and Organizational Psychology: Personnel Psychology. London: Sage Publications Ltd, 2001

21 Sonnentag S, Frese M. Performance concepts and performance theory. In: Sonnentag S, ed. Psychological Management of Individual Performance. Chichester: John Wiley \& Sons, Ltd, 2002; $1-25$

22 Nerdinger FW, Blickle G, Schaper N. Arbeits-und Organisationspsychologie. Berlin: Springer, 2011

23 Davenport D, Henderson W, Mosca C, Khuri S, Mentzerjr R. Risk-adjusted morbidity in teaching hospitals correlates with reported levels of communication and collaboration on surgical teams but not with scale measures of teamwork climate, safety climate, or working conditions. J Am Coll Surg 2007; 205: 778-84

24 Pollack MM, Koch MA. Association of outcomes with organizational characteristics of neonatal intensive care units. Crit Care Med 2003; 31: 1620-9
25 Adler MD, Vozenilek JA, Trainor JL, et al. Comparison of checklist and anchored global rating instruments for performance rating of simulated pediatric emergencies. Simul Healthc 2010; 6: $18-24$

26 Donoghue A, Nishisakia A, Suttona R, Halesc R, Boulet JR. Reliability and validity of a scoring instrument for clinical performance during Pediatric Advanced Life Support simulation scenarios. Resuscitation 2010; 81: 331-6

27 Wiles R, Robison J. Teamwork in primary care: the views and experiences of nurses, midwives and health visitors. J Adv Nurs 1994; 20: 324-30

28 Körner M, Bengel J. Teamarbeit und Teamerfolg bei multi-und interdisziplinären Teams in der medizinischen Rehabilitation teamwork and team success in multidisciplinary and interdisciplinary teams in medical rehabilitation. Rehabilitation 2004; 43: 348-57

29 Mishra A, Catchpole K, Dale T, McCulloch P. The influence of nontechnical performance on technical outcome in laparoscopic cholecystectomy. Surg Endosc 2007; 22: 68-73

30 Liberati A, Altman DG, Tetzlaff J, et al. The PRISMA statement for reporting systematic reviews and meta-analyses of studies that evaluate health care interventions: explanation and elaboration. PLoS Med 2009; 6: e1000100

31 Tschan F, Semmer NK, Gautschi D, Hunziker P, Spychiger M, Marsch SU. Leading to recovery: group performance and coordinative activities in medical emergency driven groups. Hum Perform 2006; 19: 277-304

32 Thomas EJ. Improving teamwork in healthcare: current approaches and the path forward. Br Med J 2011; 20: 647-50

33 Buckley S, Coleman J, Davison I, et al. The educational effects of portfolios on undergraduate student learning: a Best Evidence Medical Education (BEME) systematic review. BEME Guide No. 11. Med Teach 2009; 31: 282-98

34 Downs SH, Black N. The feasibility of creating a checklist for the assessment of the methodological quality both of randomised and non-randomised studies of health care interventions. J Epidemiol Community Health 1998; 52: 377-84

35 Kirk RE. Promoting good statistical practices: some suggestions. Educ Psychol Meas 2001; 61: 213-8

36 ElBardissi AW, Wiegmann DA, Henrickson S, Wadhera R, Sundt Iii TM. Identifying methods to improve heart surgery: an operative approach and strategy for implementation on an organizational level. Eur J Cardiothorac Surg 2008; 34: 1027-33

37 Manojlovich M, Antonakos CL, Ronis DL. Intensive care units, communication between nurses and physicians, and patients' outcomes. Am J Crit Care 2009; 18: 21-30

38 Tschan F, Semmer NK, Gurtner A, et al. Explicit reasoning, confirmation bias, and illusory transactive memory: a simulation study of group medical decision making. Small Group Res 2009; 40: $271-300$

39 Burtscher MJ, Wacker J, Grote G, Manser T. Managing nonroutine events in anesthesia: the role of adaptive coordination. Hum Fact 2010; 52: 282-94

40 Burtscher MJ, Manser T, Kolbe M, et al. Adaptation in anaesthesia team coordination in response to a simulated critical event and its relationship to clinical performance. $\mathrm{Br} J$ Anaesth 2011; 106: 1-6

41 Manser T, Harrison TK, Gaba DM, Howard SK. Coordination patterns related to high clinical performance in a simulated anesthetic crisis. Anesth Analg 2009; 108: 1606-15

42 Carlson J, Min E, Bridges D. The impact of leadership and team behavior on standard of care delivered during human patient 
simulation: a pilot study for undergraduate medical students. Teach Learn Med 2009; 21: 24-32

43 Marsch SCU, Müller C, Marquardt K, Conrad G, Tschan F, Hunziker PR. Human factors affect the quality of cardiopulmonary resuscitation in simulated cardiac arrests. Resuscitation 2004; 60: $51-6$

44 Catchpole KR, Giddings AE, Wilkinson M, Hirst G, Dale T, de Leval MR. Improving patient safety by identifying latent failures in successful operations. Surgery 2007; 142: 102-10

45 Catchpole K, Mishra A, Handa A, McCulloch P. Teamwork and error in the operating room: analysis of skills and roles. Ann Surg 2008; 247: 699-706

46 Schraagen JM, Schouten T, Smit M, et al. A prospective study of paediatric cardiac surgical microsystems: assessing the relationships between non-routine events, teamwork and patient outcomes. Br Med J 2011; 20: 599-603

47 Mazzocco K, Petitti DB, Fong KT, et al. Surgical team behaviors and patient outcomes. Am J Surg 2009; 197: 678-85

48 Thomas E, Sexton J, Lasky R, Helmreich R, Crandell D, Tyson J. Teamwork and quality during neonatal care in the delivery room. J Perinatol 2006; 26: 163-9

49 Westli H, Johnsen B, Eid J, Rasten I, Brattebø G. Teamwork skills, shared mental models, and performance in simulated trauma teams: an independent group design. Scand J Trauma Resusc Emerg Med 2010; 18: 47

50 Burtscher MJ, Kolbe M, Wacker J, Manser T. Interactions of team mental models and monitoring behaviors predict team performance in simulated anesthesia inductions. J Exp Psychol Appl 2011; 17: 257

51 Siassakos D, Fox R, Crofts JF, Hunt LP, Winter C, Draycott TJ. The management of a simulated emergency: better teamwork, better performance. Resuscitation 2011; 82: 203-6

52 Künzle B, Zala-Mezo E, Kolbe M, Wacker J, Grote G. Substitutes for leadership in anaesthesia teams and their impact on leadership effectiveness. Eur J Work Organ Psychol 2010; 19: 505-31

53 Manser T, Howard SK, Gaba DM. Adaptive coordination in cardiac anaesthesia: a study of situational changes in coordination patterns using a new observation system. Ergonomics 2008; 51: 1153-78

54 Kalisch BJ, Curley M, Stefanov S. An intervention to enhance nursing staff teamwork and engagement. J Nurs Adm 2007; 37: 77-84

55 McCulloch P, Mishra A, Handa A, Dale T, Hirst G, Catchpole K. The effects of aviation-style non-technical skills training on technical performance and outcome in the operating theatre. Qual Saf Health Care 2009; 18: 109-15

56 Wolf FA, Way LW, Stewart L. The efficacy of medical team training: improved team performance and decreased operating room delays: a detailed analysis of 4863 cases. Ann Surg 2010; 252: 477-83

57 Morey JC, Simon R, Jay GD, et al. Error reduction and performance improvement in the emergency department through formal teamwork training: evaluation results of the MedTeams project. Health Serv Res 2002; 37: 1553-81

58 Nielsen PE, Goldman MB, Mann S, et al. Effects of teamwork training on adverse outcomes and process of care in labor and delivery: a randomized controlled trial. Obstet Gynecol 2007; 109: 48-55

59 Phipps MG, Lindquist DG, McConaughey E, O'Brien JA, Raker CA, Paglia MJ. Outcomes from a labor and delivery team training program with simulation component. Am J Obstet Gynecol 2011; 206: $1-7$

60 Fernandez Castelao E, Russo SG, Cremer S, et al. Positive impact of crisis resource management training on no-flow time and team member verbalisations during simulated cardiopulmonary resuscitation: a randomised controlled trial. Resuscitation 2011; 82: 1338-43

61 Burke CS, Stagl KC, Salas E, Pierce L, Kendall D. Understanding team adaptation: a conceptual analysis and model. J Appl Psychol 2006; 91: 1189-207

62 Bortz J, Döring N. Forschungsmethoden und Evaluation für Human-und Sozialwissenschaftler. Berlin: Springer Verlag, 2006

63 Greve W, Wentura D. Wissenschaftliche Beobachtung: Eine Einführung. Weinheim: BeltzPVU, 1997

64 Cooper S, Cade J. Predicting survival, in-hospital cardiac arrests: resuscitation survival variables and training effectiveness. Resuscitation 1997; 35: 17-22

65 Landon BE, Normand SLT, Blumenthal D, Daley J. Physician clinical performance assessment. J Am Med Assoc 2003; 290: 1183-9

66 Gordon TJ. The Delphi Method. In: Glenn JC, ed. Futures Research methodology series. Washington, D. C.: United Nations University; 1994

67 Buljac-Samardzic M, Dekker-van Doorn CM, Van Wijngaarden JDH, Van Wijk KP. Interventions to improve team effectiveness: a systematic review. Health Policy 2010; 94: 183-95

68 Easterbrook PJ, Gopalan R, Berlin J, Matthews DR. Publication bias in clinical research. Lancet 1991; 337: 867-72

69 Ogles BM, Lunnen KM, Bonesteel K. Clinical significance: history, application, and current practice. Clin Psychol Rev 2001; 21: 421-46

70 Lingard L, Whyte S, Espin S, Ross Baker G, Orser B, Doran D. Towards safer interprofessional communication: constructing a model of 'utility' from preoperative team briefings. J Interprof Care 2006; 20: 471-83

71 Cohen J. Statistical Power Analysis for the Behavioral Sciences. Hillsdale, NJ: Lawrence Erlbaum, 1988

72 Schraagen JM. Dealing with unforeseen complexity in the OR: the role of heedful interrelating in medical teams. Theor Issues Ergon Sci 2011; 12: 256-72

73 Rasch B, Friese M, Hofmann W, Naumann E. Quantitative Methoden: Einfuhrung in die Statistik 1. 2 Edn. Heidelberg: Springer Medizin Verlag, 2006

74 Walker DA. JMASM9: converting Kendall's tau for correlational or meta-analytic analyses. J Mod Appl Stat Meth 2003; 2: $525-30$ 